\title{
JUST HEALTH CARE RATIONING: A DEMOCRATIC DECISIONMAKING APPROACH
}

\author{
LEONARD M. FLECK $\dagger$
}

\section{INTRODUCTION}

Michael S. was born in 1984 to unmarried teenage parents who were without health insurance. He was born with necrotic small bowel syndrome. Surgery at birth determined that he would not be able to process food in the normal way. Hence, he would have to remain in an intensive care unit, fed via total parenteral nutrition (TPN). After six months the hospital administrator approached the attending physician and pointed out that Michael was responsible for $\$ 250,000$ in uncompensated care costs. Michael could live another six to eighteen months, which would mean potential uncompensated care costs of one million dollars. The administrator reminded the physician that this was the only hospital in town that provided charity care to the poor, and that if Michael remained in the hospital then the emergency room would have to be closed to all the poor, except those with true life-threatening medical problems. The state was willing to care for Michael and place him in a nursing home, but it would not provide TPN, which would mean Michael would die of infection and/or starvation within two weeks. ${ }^{1}$

This case raises numerous profound moral and political issues. How should a good doctor respond to this administrator, a doctor who wants to be both just and caring, a doctor who wants to be both a fair allocator of limited health resources and a loyal advocate of this patient's best interests? How should a good administrator respond to a doctor or parents who want Michael to live as long as possible when that administrator is responsible for meeting a broad range of other legitimate health needs that are, admittedly, not now visibly embodied, as is Michael? If the members of this community

† Associate Professor in the Center for Ethics and Humanities in the Life Sciences at Michigan State University. Ph.D. in Philosophy, St. Louis University, 1975. The author's main areas of teaching and research are medical ethics and justice/health care policy.

1 The original version of this case comes from an article by Lawrence B. McCullough, Moral Dilemmas and Economic Realities, HOSP. \& HEALTH SERVICES ADMIN., Sept.-Oct. 1985, at 63, 68-69. 
want to be both just and caring, then how ought they respond to Michael's needs? We need to keep in mind that there are hundreds of infants in this community who have serious unmet or inadequately met health needs; and if the members of this community want to support Michael generously to show that they care, they must also confront candidly that they risk treating all these other children unjustly if they are unwilling to treat them with equal generosity. The astute reader with a little philosophic training might object at this point that there is a radical difference between justice and generosity, and that a generous response by the community ought not raise questions about justice. That response, however, is too easy. Generosity is morally praiseworthy only if the more basic demands of health care justice have been satisfied.

There are two variations on the case of Michael that need to be considered. First, if we know for certain that Michael is doomed to die by the age of two, then can we think of ourselves as just and caring if we refuse to spend that first $\$ 250,000$ ? That is, if we provide Michael with comfort care only and allow him to die shortly after birth, would we have treated Michael unjustly?

The alternative scenario arises when death is uncertain. ${ }^{2}$ Suppose that Michael would die by age two from the TPN treatments, which eventually fatally compromise liver function, but that a surgeon was willing to do a liver transplant at a cost in excess of $\$ 300,000$, which would allow Michael to live to age four. At that point in time (still in the future) the surgeon is also prepared to attempt a liver and bowel transplant at a cost that might approach $\$ 500,000$. If Michael were denied one or both of these transplants, would we be justifiably accused of treating him unjustly and uncaringly?

The reader will note that $I$ have deliberately left unspecified the "we" in the preceding paragraphs, for that is the central problem to be addressed in this essay. In a liberal society that claims to be just and caring, who ultimately should have responsibility for determining what counts as a fair allocation of always limited health resources? My reply is that in a liberal democratic society this ought to be the responsibility of each and every citizen, and that it is through processes of informed public discourse that such decisions ought to be made.

2 This scenario was called to my attention by a nurse at a conference sponsored by the National Kidney Foundation of Michigan in June of 1991. I was speaking at that conference and had used the story of Michael S. 
In affirming this view I am rejecting the view that any purely private decisionmaking mechanism is morally defensible, whether that is an impersonal mechanism such as markets, or more personal approaches wherein doctors, families, administrators, insurers, or employers negotiate these decisions. I am not rejecting absolutely such private decisionmaking mechanisms; rather, my claim is that their appropriate use will be circumscribed by the decisions that emerge from this broader process of informed public discourse. Similarly, I am rejecting the view that governmental mechanisms, whether legislative, judicial, or administrative, should be the primary mechanisms through which these decisions are made, though I readily concede that they have a necessary role to play in implementing and legitimating the decisions that are a product of public conversation. Finally, although expertise related to health economics, organizational behavior, and other disciplines is necessary to inform the public's dialogue, I reject the view that experts of any kind should have decisional authority regarding allocational and rationing decisions, except in a limited range of circumstances where such authority has been granted as a result of broad, democratic public conversations.

This essay begins with a long prefatory argument; its purpose is to lay out the intellectual presuppositions that provide the framework for the central problem of this essay. Specifically, I need to show that the problem of health care rationing is fundamentally $a$ moral and political problem, and not fundamentally an economic, managerial, organizational, or technological problem (i.e., the kind of problem that might best be solved by tinkering with economic incentives, restructuring delivery systems and professional behavior, or by technological ingenuity that finds innovative ways of unclogging occluded arteries more efficiently). For if any of these ways of characterizing the problem were ultimately correct, then some assortment of economists, bureaucrats, and technocrats would have ultimate responsibility for finding an appropriate resolution that would be expressed through market reforms, tighter regulations, and detailed practice guidelines. That is, the informed democratic consensus approach which I advocate would then be entirely wrongheaded. But if health care rationing is fundamentally a moral and political problem, then a democratic consensus approach is at least prima facie reasonable.

Some readers might find intellectually disconcerting the juxtaposition of morality and politics, especially if this carries the suggestion that some of our fundamental moral beliefs regarding 
justice might be a product of some sort of democratic conversation. In my judgment, however, this is precisely the view that is required if we are going to come to an uncoerced agreement on matters of social policy in a liberal democratic culture. The political philosophical tradition which I draw from is that of John Dewey, the later Rawls, and Richard Rorty. ${ }^{3}$ This is essentially a pragmatic philosophic tradition that eschews metaphysically or theologically based

${ }^{3}$ For example, John Dewey argues:

The need for security compels men to fasten upon the regular in order to minimize and to control the precarious and fluctuating. ... Philosophies have too often tried to forego the actual work that is involved in penetrating the true nature of experience, by setting up a purely theoretical security and certainty. [This has] influence[d] ... the traditional philosophic preference for unity, permanence [and] universals, over plurality, change and particulars ....

JOHN DEWEY, EXPERIENCE AND NATURE at xiii (2d ed. 1929). Dewey also believes:

[T] ]he first problem for philosophy would seem to be to clear itself of further responsibility for the doctrine that the supreme issue is whether values have antecedent Being. . . . [T] he genuine issue is not whether certain values, associated with traditions and institutions, have Being already ..., but what concrete judgments we are to form about ends and means in the regulation of practical behavior.

JOHN DEWEY, THE QUEST FOR CERTAINTY 47 (1930); see also JOHN DEWEY, HUMAN NATURE AND CONDUCT 282-83 (1922) [hereinafter DEWEY, HUMAN NATURE]. According to Rawls:

[J]ustifying a conception of justice is not primarily an epistemological problem. The search for reasonable grounds for reaching agreement rooted in our conception of ourselves and in our relation to society replaces the search for moral truth interpreted as fixed by a prior and independent order of objects and relations, whether natural or divine, an order apart and distinct from how we conceive ourselves. . . What justifies a conception of justice is not its being true to an order antecedent to and given to us, but its congruence with our deeper understanding of ourselves and our aspirations, and our realization that, given our history and the traditions embedded in our public life, it is the most reasonable doctrine for us.

John Rawls, Kantian Constructivism in Moral Theory, 77 J. PHIL. 515, 519 (1980) [hereinafter Rawls, Kantian Constructivism]. Rawls further states:

[A]s a practical political matter no general moral conception can provide a publicly recognized basis for a conception of justice in a modern democratic state. .. . [A] workable conception of political justice . . . must allow for a diversity of doctrines and the plurality of conflicting, and indeed incommensurable, conceptions of the good affirmed by the members of existing democratic societies.

John Rawls, Justice as Fairness: Political Not Metaphysical, 14 PHIL. \& PUB. AFF. 223, 225 (1985); see also Richard Rorty, The Priority of Democracy to Philosophy, in THE VIRGINIA STATUTE FOR RELIGIOUS FREEDOM 257, 271 (Merrill D. Peterson \& Robert C. Vaughan eds., 1988) (arguing that "reflective equilibrium is all we need try forthat there is no natural order of justification of beliefs, no predestined outline for argument to trace"). 
rational certitude for our moral and political beliefs. Instead, this tradition asserts that it is enough for a liberal democratic society to ground its moral and political beliefs in reasoned agreement since it can never escape the contingencies of its culture. From a Deweyan perspective, we can never get beyond experimental reason to some eternal moral truth. ${ }^{4}$ For Rawls, our objective is not to find a conception of justice suitable for all societies, but rather, "to settle a fundamental disagreement over the just form of basic institutions within a democratic society under modern conditions. ${ }^{n 5}$ For our purposes we are seeking a conception of health care justice that speaks to our disagreements regarding a fair distribution of health care in our society. I now turn to my expanded argument.

\section{Health Care: A Moral GoOd, A Public GoOd}

How health care is distributed is a moral matter; specifically, it is a matter of social justice. This is a rejection of the claim that health care is simply another commodity properly distributed in accord with ability to pay. There seems to be a widely agreed upon moral judgment in our society, for example, that it would be fundamentally wrong to auction off transplantable hearts or livers to the highest bidder. Similarly, the case of Michael should not occasion even minimal moral reflection if health care is properly distributed in accordance with ability to pay. But the fact is that we are morally troubled when we are confronted with cases like that of Michael. This is not just a psychological fact. One moral reason would seem to be that we have very effective health technologies today that often make the difference between life and death. This is one of those contingent facts that was not true prior to 1900. It is terribly unfortunate when nature causes the death of a child. That does not trouble our conscience. But when we conspire with nature to allow the death of a child, then our social conscience ought to be troubled. Another moral reason, as Daniels has argued, is that access to needed health care protects fair equality of opportunity in our society in much the same way that education does:

[E]ducational needs, like health-care needs, differ from other basic needs, such as the need for food and clothing, which are more equally distributed between persons. The combination of their

${ }^{4}$ See DEWEY, HUMAN NATURE, supra note 3, at 282.

${ }^{5}$ Rawls, Kantian Constructivism, supra note 3 , at 518. 
unequal distribution and their great strategic importance for opportunity puts these needs in a separate category from those basic needs we can expect people to purchase from their fair income shares, like food and shelter. ${ }^{6}$

My claim that the distribution of health care is a matter of social justice is also a rejection of the view that it is a matter of social beneficence or charity. In other words, allowing Medicaid coverage of the poor to vary from state to state in accord with the charitable impulses of local taxpayers and legislators is unjust. I concede that this latter claim is a legitimate object of social controversy, though I would argue that the legitimate controversy pertains to where we draw the line between health services that our society is justly obligated to guarantee to all and other health services that are justifiably distributed through markets or charitable social inclinations. For many of us it is difficult to discern the moral justification for allowing Michael's fate to be determined by whether he is a resident of Kansas or Missouri. ${ }^{7}$

Next, my claim is that access to health care is properly thought of as a public interest, and hence, as a matter of social justice. The considerations that support this contention are the following. First, we have a first-rate health care system because of huge public investments (i.e. subsidies) in medical education, medical research, medical technology, and the building of modern health care facilities. Second, we use the power of the state to grant monopoly power to physicians to practice medicine. Third, we justifiably speak of health care as a public interest because individuals as such are not able to protect this interest adequately on their own in our society. Would the elderly, for example, the vast majority of whom have one or more chronic illnesses (and are not employed), have

6 NORMAN DANiels, JUST HEALTH CARE 46-47 (1985). For further arguments in support of the claim that the way health care is distributed is a moral problem, see 1 PRESIDENT'S COMM'N FOR THE STUDY OF ETHICAL PROBLEMS IN MEDICINE AND Biomedical and Behavioral RESEarch, Securing ACcess to Health CaRe 1-47 (1983) (arguing, id. at 16-17, that "[e]thical concern about the distribution of health care derives from the special importance of health care in promoting personal wellbeing," in broadening "a person's range of opportunities," in relieving "worry . . . by supplying reliable information about [a patient's] health," and in expressing and nurturing "bonds of empathy and compassion").

${ }^{7}$ For additional support of my claim that the distribution of health care is a matter of social justice and not simply social beneficence, see my other writings on the subject: Leonard M. Fleck, Just Health Care (I): Is Beneficence Enough?, 10 THEORETICAL MED. 167 (1989), and Leonard M. Fleck, Just Health Care (II): Is Equality Too Much?, 10 THEORETICAL MED. 301 (1989). 
access to adequate health care if they had to rely entirely upon private insurance for that access rather than Medicare? I remind the reader that those over age sixty-five made up about thirteen percent of the population in 1990 but were responsible for about twenty-nine percent of health expenditures that year, or about 200 billion dollars. $^{8}$

From all these observations I want to draw a relatively unstartling conclusion; namely, there are legitimate public interests in health care that need protection through public policy and these are moral interests as well. Another way to put this conclusion is that society should not be indifferent about the distribution of health care in the way society is indifferent about the distribution of most consumer goods.

\section{Health Care Rationing: AN Inescapable SOCIAL POLICY PROBLEM}

There are limits to what we as a society ought to spend on health care because there are other competing social goods that make legitimate claims on that finite set of dollars. Hence, the need for health care rationing is inescapable. ${ }^{9}$ Here we need to devote some attention to definitional matters.

If our concept of rationing includes both price and non-price rationing, then our claim about the inescapability of health care

${ }^{8}$ See Seniors and Health Costs, USA TODAY, Jan. 8, 1992, at 1A.

${ }^{9}$ What I shall refer to as the generic argument for health care rationing is best made by Fuchs and Thurow. See, e.g., VICTOR R. FUCHS, Who SHALL LIVE?: HEALTH, ECONOMICS, AND SOCIAL CHOICE 29 (1974) (arguing that the problems of access to health care must be analyzed from "an economic point of view": "we must recognize the scarcity of resources and the need to allocate them as efficiently as possible. We must recognize that we can't have everything."); Victor R. Fuchs, The "Rationing" of Medical Care, 311 NEw ENG.J. MED. 1572, 1573 (1984) (asserting that in the future, health plan managers, hospital administrators, insurance company executives, and government officials will use "considerably more systematic analyses regarding the location of facilities, investment in equipment, training of specialists, and designing of screening programs and treatment protocols ... to help them make difficult decisions about the allocation of scarce resources"); Lester C. Thurow, Learning to Say "No," 311 NEw ENG.J. MED. 1569, 1569 (1984) (arguing that "new medical techniques require a shift in standard medical practice [and that i]nstead of stopping treatments when all benefits cease to exist, physicians must stop treatments when marginal benefits are equal to marginal costs"); Lester C. Thurow, Medicine Versus Economics, 313 NEW ENG. J. MED. 611, 612 (1985) (contending that in order to keep health care costs affordable the current "retrospective fee-for-service, insured-reimbursement system" must be replaced with payers (government or corporation) only providing "so-much-per-patient payments"). 
rationing becomes uninteresting. Rationing of this kind would not inspire moral or political outrage. Michael Reagan makes some helpful analytic points. He defines rationing as "a mode of nonprice distribution of particular services among particular individuals."10 Here he is endorsing Robert Blank's point that rationing involves "making a choice among the claims of individuals who are competing for resources limited by public policy."11 Reagan goes on to note that rationing is "inherently comparative," and it involves a situation in which community policymakers seek to achieve an equitable distribution of what is a scarce resource. ${ }^{12}$ Finally, Reagan wants to distinguish rationing decisions from allocation decisions, the latter being administrative decisions about the relative size of budgets. ${ }^{13}$ There is one other element of our public conception of rationing that needs to be made explicit, what Lawrence Brown refers to as "cost-effective retrenchment." 14 Under this rubric, rationing means "the deliberate, systematic withholding of beneficial goods or services from some elements of the population on the grounds that society cannot afford to extend them."15

When we combine what Blank, Brown, and Reagan have to say about rationing, we can more readily appreciate why physicians and politicians want to avoid health care rationing. More specifically, rationing means that identified individuals, like Michael, who can command our sympathies, are denied potentially beneficial medical care, which means either that they are condemned to premature death or to substantial unnecessary suffering. By way of contrast, we are unmoved when American Medical News reports that the uninsured poor have a ten to fifteen percent excess death rate from cancer because they fail to obtain early primary care that they cannot afford. ${ }^{16}$ These are faceless individuals whose deaths will not be publicly recognized at all, much less seen as being unjust.

In addition, rationing usually means that physicians-individuals who are supposed to be loyal advocates of their patients' best

${ }^{10}$ Michael D. Reagan, Health Care Rationing and Cost Containment Are Not Synonymous, 9 POL'Y STUD. REV. 219, 223 (1990).

11 RoBert H. BLANK, RATIONING MEDICINE 78 (1988).

12 See Reagan, supra note 10 , at 223.

13 See id.

${ }^{14}$ Lawrence D. Brown, The National Politics of Oregon's Rationing Plan, HEALTH AFF., Summer 1991, at 28, 30-31.

${ }^{15} \mathrm{Id}$. at 30.

${ }^{16}$ See Deborah S. Pinkney, ACS Report: Poor Caught in Cancer Trap, AM. MED. NEws, July 28, 1989, at 1, 38-39. 
interests-will either make or acquiesce in decisions to deny individuals potentially beneficial medical care. Similarly, rationing means that government, which is supposed to protect equally the rights of all its citizens, will deny an identified citizen potentially life-sustaining medical care by saying, in effect, that Michael's needs count for less than the needs of some other citizen. Fourth, rationing means that government will deny one of its citizens lifesustaining medical care on the basis of an arbitrary budgetary limit.

Finally, rationing means that a liberal, democratic government will appeal to some conception of equity to justify its rationing decisions, and this conception of equity may not be endorsed by those citizens whose lives are directly affected by these rationing decisions. Liberal governments are supposed to be assiduously neutral among competing moral conceptions of the right and good. Further, how legitimate is a conception of equity, used to justify rationing decisions, which is a product of interest group power and political skill? After these considerations, the reader should not be surprised that health care rationing would be an object of intense obloquy, that every effort would be made to escape "the need" for health care rationing, and that virtually any other approach to health care cost containment would be preferable to rationing. This is a conclusion I reject for reasons that I will address later. ${ }^{17}$

What are the alternatives to health care rationing? Marcia Angell wrote one of the early papers delineating the possibilities, ${ }^{18}$ and her analysis is echoed in numerous others. ${ }^{19}$ Her basic conclusions are that there is enormous waste and inefficiency in the health care system, that all this waste and inefficiency must be rooted out before we contemplate denying beneficial health care to patients, and that this can be accomplished through health planning, technology assessment, and practice guidelines, among other things. ${ }^{20}$

${ }^{17}$ See infra text accompanying notes 39-51.

18 See Marcia Angell, Cost Containment and the Physician, 254 JAMA 1203 (1985).

19 See, e.g., Brown, supra note 14, at 49 (concluding that " [c] ritics can fairly charge that Oregon surrendered to rationing without waging a serious war on the supply-side sources of rising health costs"); Arnold S. Relman, Is Rationing Inevitable?, 322 NEW ENG. J. MED. 1809, 1810 (1990) (asserting that "there are vast savings to be made through the elimination of unnecessary services and facilities"); Arnold S. Relman, The Trouble With Rationing, 323 NEw ENG. J. MED. 911, 912 (1990) (advocating changing "certain features of the [health care] system" to eliminate "duplication and waste of resources and ... excessive overhead costs").

${ }^{20}$ See Angell, supra note 18, at 1206-07. 
Both a "technical response" and "moral response" can be given to this line of argument. The "technical response" is given very adequately by Schwartz and Aaron. ${ }^{21}$ They assert that any savings achieved by efficiency measures represent a one-time saving that reduces the base for health care spending but does nothing to alter the underlying trends that inflate health care costs. ${ }^{22}$ For the past twenty years health expenditures have been increasing annually at more than twice the rate of inflation as measured by the Consumer Price Index (CPI). They are projected to increase at a rate of ten percent for each year between 1992 and $1995,{ }^{23}$ which means that if we could achieve an instantaneous thirty percent base reduction this year (the amount Angell believes the base could be reduced by, though not instantaneously), it would take only 3.5 years to restore our projected 1992 base of 818 billion dollars.

If Aaron and Schwartz are right, then what is the attraction of achieving such fleeting efficiencies? Essentially, all the approaches to health care cost containment touted by assorted economists, policy analysts, and physicians have the virtue of objectivity attached to them. That is, it is markets or scientific research that are yielding these cost-controlling efficiencies in an impersonal, value-neutral, apolitical way. No doubt there are individuals who are adversely

${ }^{21}$ See, e.g., Henry Aaron \& William B. Schwartz, Rationing Health Care: The Choice Before Us, 247 SCIENCE 418, 419 (1990) ("Various methods [which] have been proposed for cutting costs and improving efficiency ... . all promise to arrest or slow the growth of medical costs only temporarily."); William B. Schwartz, The Inevitable Failure of Current Cost-Containment Strategies, 257 JAMA 220, 220-21 (1987) ("[E]ven if all useless care were gradually eliminated, we could anticipate only a temporary respite from rising costs unless the forces sustaining the real rate of change-chiefly technologic innovation and rising input prices-were simultaneously brought under control."). Daniel Callahan offers an expanded version of this argument with which I fully concur:

The most basic contradiction is that at the same time that we desire to control costs, we want also to improve the quality and extent of, and access to, health care. . . . At the same time that we try to contain costs, and avoid rationing, we continue to affirm those values that drive up costs.

Daniel Callahlan, What Kind of Life?: The Limits of Medical Progress 78-79 (1990).

${ }^{22}$ See Aaron \& Schwartz, supra note 21, at 419.

${ }^{23}$ See Sally T. Sonnefeld et al., Projections of National Health Expenditures Through the Year 2000, 13 HEALTH CARE FINANCING REV. 1, 4 (1991). For purposes of my example I restricted myself to 1992-95. These researchers project a slow decline to 7-8\% annual increases in health expenditures for the latter half of the decade, which will still yield national health expenditures of 1.6 trillion dollars by the year 2000 , equal to $16.4 \%$ of GNP then. See id. For longer range projections, see Daniel R. Waldo et al., Health Spending Through 2030: Three Scenarios, HEALTH AFF., Winter 1991, at 231. 
affected by these cost-containing devices, but these will not be politically visible individuals because their death or untreated disease will be seen as simply unfortunate, a mere extension of the natural lottery. No agent of society will have identified them as being less worthy of receiving expensive, life-prolonging medical care. Hence, there will be no need for bitter and divisive public debate about health care rationing, especially with regard to identified individuals like Michael. More specifically, these approaches to containing health care costs avoid having to confront health care choices as moral problems.

At this point three questions need to be posed. First, has the need for health care rationing really been avoided through these technical approaches to cost containment? My response is that the rationing has simply been masked so that it is hidden and implicit. This is societal self-deception on a massive scale. Second, has health care cost-containment been successfully avoided as a moral problem? Again, my response is that the moral problem of health care justice has been avoided, and this is something open to legitimate moral criticism. Third, did our earlier discussion of the conception of rationing by Reagan, Blank, and Brown really capture what was morally and politically most objectionable about health care rationing? No! What is most objectionable about health care rationing is that it is not self-imposed. Rather, the healthy, wealthy, and relatively politically powerful impose rationing schemes upon the sick, the poor, and the relatively politically powerless. The moral and political virtue of the informed democratic consensus approach to health care rationing for which I shall argue is that the rationing principles and protocols that emerge from that conversation will be freely self-imposed, explicit, consistently applied to all in that community, and a product of a shared conception of health care justice that will emerge from a conversation among undominated equals.

\section{If Health Allocation, Then Health Rationing:}

AN INESCAPABLE IMPLICATION

It is my contention that allocation decisions ultimately imply rationing decisions, and that the need for health care rationing really is inescapable. This is not a conclusion that Michael Reagan will accept, for he wants to make a sharp distinction between 
allocation and rationing. ${ }^{24}$ At the level of allocation decisions there are no identified individuals; impersonal rules and impersonal equations are what generate results. Reagan chides Fuchs and Thurow and other health economists for confusing these two levels. $^{25}$ I am inclined, however, to agree with Calabresi and Bobbitt that this distinction serves as a convenient device for societal self-deception that allows us to believe we are not making any invidious moral choices. ${ }^{26}$

For Calabresi and Bobbitt the challenge to society is "to make allocations in ways that preserve the moral foundations of social collaboration."27 The title of their book, Tragic Choices, comes from their claim that any allocational choices will ultimately violate some deeply held societal value. "Action in the context of necessary scarcity brings ultimate values, the values by which a society defines itself, into conflict." ${ }^{28}$ They distinguish what they call first-order and second-order allocation decisions, decisions regarding how much of a scarce good will be produced and decisions regarding who will get that good. ${ }^{29}$ They also point out that societies typically make decisions at these two levels separately so that a different mixture of values exists at each level. ${ }^{30}$ So long as these levels can be kept separate, as far as societal consciousness is concerned, the illusion can be preserved that none of society's basic values have been disregarded. ${ }^{31}$ For example, we might stint on mine safety because the price of coal has been declining and we want to preserve those jobs and the business investment. That means the lives of some men will be placed at risk, but we view that risk as acceptable in light of the benefits that it produces. Then, if there is a mine accident, we will spare virtually no expense in a rescue effort which we may well know is likely to be futile. Still, in that way we will have affirmed that human life is priceless at that

${ }^{24}$ See Reagan, supra note 10 , at 224.

${ }^{25} \mathrm{See}$ id. at 224 (rejecting Fuch's notion that rationing is "reducing the volume of services" and Thurow's belief that rationing is a process of making choices based on a "cost benefit analysis").

${ }^{26}$ See Guido Calabresi \& Philip BobBIT, TRagic Choices 20 (1978).

27 Id. at 18 .

${ }^{28} \mathrm{Id}$.

${ }^{29}$ See id. at 19.

${ }^{30}$ See id. at 20.

${ }^{31}$ See id. (" $[\mathrm{W}]$ hen the first-order determination of a tragic choice appears to be no more than a dependent function of the second order, it will usually be the case that the connection is illusory, serving to obscure the fact of tragic scarcity and-while the illusion lasts-evading the tragic choice."). 
level, though we effectively denied the same value at the safety allocation level. Enterprising reporters might embarrass us by putting both decisions before the public at once. Barring that, however, the result will seem "necessary, unavoidable, rather than chosen" which will "convert what is tragically chosen into what is merely a fatal misfortune." 32 Note that Calabresi and Bobbitt are honest enough to admit that societal choices have been made here and these choices reflect some pattern of values.

What is it that Reagan hopes to achieve by making this sharp distinction between allocation and rationing decisions? So long as we focus on allocation decisions, getting rid of waste and inefficiency in our health care system, we will not "have any compelling public interest reason for instituting a system of explicit rationing." 33 I contend, however, that what we would have instead is implicit, hidden or invisible rationing wherein individuals would still be denied needed, potentially beneficial medical care, though they would not feel they had been denied that care. Implicit rationing has nothing to recommend it, morally or politically. Let us consider some examples.

There are about ten million $x$-ray examinations done each year in the United States using a contrast medium that costs ten dollars per procedure. About 300 people will have a fatal reaction to that contrast medium, however. There is another contrast medium that can be used that costs $\$ 100$ per procedure and that will reduce fatal reactions to thirty per year. It has been estimated, however, that the switch to this medium would add 1 billion dollars to the cost of health care in the United States. ${ }^{34}$ Should we think of such an expenditure as being wasteful or outrageously expensive when this

32 Id. at 21 .

33 Reagan, supra note 10, at 228. In this Issue, Blustein and Marmor cogently argue against what they describe as the "bureaucratically sanctioned linguistic drift" and "conceptual hodgepodge" that is represented by the phrase "wasteful [medical] care." Jan Blustein \& Theodore R. Marmor, Cutting Waste by Making Rules: Promises, Pitfalls, and Realistic Prospects, 140 U. PA. L. REV. 1543, 1545 (1992). They too argue that this phrase is used to mask what are often ethically troubling allocation decisions. Getting rid of medical waste and inefficiency looks like a morally and politically painless panacea for the problem of escalating health care costs. It is not!

${ }^{34}$ See Aaron \& Schwartz, supra note 21, at 422; see also Earl P. Steinberg et al., Safety and Cost Effectiveness of High-Osmolality As Compared with Low-Osmolality Contrast Material in Patients Undergoing Cardiac Angiography, 326 NEW ENG. J. MED. 425 (1992). These authors note a twenty-fold cost differential between the two types of contrast material. They also note that patients over age sixty with unstable angina have a $\mathbf{3 . 5}$ times greater chance of a severe reaction to the less expensive contrast material. See id. at 425 . 
means a cost of three million dollars per life saved? This question does not seem to have any obvious, rationally compelling answer. The choice really needs further specification, and some other social values need to be brought in before the decision-making process can begin. What if seventy percent of private insurance firms included the more expensive contrast medium in their benefit packages but Medicare and Medicaid did not? Should this be morally troubling? Should those in the middle class who are not eligible for Medicare or Medicaid acquiesce to this as just another budgetary choice, though the obvious consequence will be a number of premature deaths among the old and the poor? Is there anything that would excuse us from taking moral responsibility for a decision like this, other than our pretending that it is not really a decision?

The Medicare scenario is really the more interesting one for our purposes since, under Diagnosis-Related Groups (DRGs), the federal government would say nothing at all about which contrast medium ought to be used. How then would Reagan conceptualize this situation-allocation or rationing? The financial incentives are clear. Hospitals would "lose money" if they provided the more expensive medium to all their patients. What if, as seems likely in a real world scenario, more educated and assertive Medicare patients asked specifically for the more expensive medium, and hospitals generally acquiesced to their choices while providing only the less expensive medium to nonassertive Medicare patients? Would Reagan describe this as rationing or prudent allocation? In my judgment it would be patent dissembling to call this anything but rationing. And if this is true, then rationing is a rampant feature of Medicare DRGs, though hidden from effective public scrutiny, as I have argued elsewhere. ${ }^{35}$

The more general conclusion I wish to draw is that even though allocation decisions in Reagan's sense will only affect "statistical individuals," these individuals will be real in the future. Failure to assess publicly alternative allocation options from a moral point of view will likely result in serious injustices. Helga Wanglie and Nancy Cruzan are two cases in point. Helga Wanglie was an eightyfive-year old woman who suffered a very serious heart attack in May

${ }^{35}$ See, e.g., Leonard M. Fleck, DRGs: Justice and the Invisible Rationing of Health Care Resources, 12 J. MED. \& PHIL. 165, 185 (1987) (asserting that in the case of DRG's, the decisions of physicians and hospital administrators regarding the allocation of life-prolonging resources to either individuals or groups of individuals is "localized," "privatized," and therefore "invisible" in that they "would not be required to publicize any 'official' allocation criteria"). 
of 1990 that resulted in her being reduced to a persistent vegetative state on a respirator in a hospital Intensive Care Unit (ICU). After five months, her physicians wanted to withdraw her from the respirator and allow her to die on the grounds that the care they were providing was medically futile. Her husband and two children protested that their mother wanted to be kept alive for as long as possible, even if in a state of bare biological existence. The result was that she survived for sixteen months at a cost in excess of $\$ 700,000 .^{36}$ Did Helga Wanglie have a just claim to resources of this magnitude in these circumstances? It is impossible to answer this question by any appeal to simply economic or efficiency criteria. This is a moral issue that must be addressed as such. We must ask at the allocative level whether any patient in a persistent vegetative state has a moral claim to anything more than comfort care, where "any patient" includes our future possible selves. For example, it is prima facie unjust that the state of Missouri would spend close to one million dollars in Medicaid funds to keep Nancy Gruzan alive for nearly eight years in a persistent vegetative state ${ }^{37}$ while providing access to Medicaid for only forty percent of those below the poverty level in Missouri. ${ }^{38}$ That one million dollars would have purchased substantial medical benefits for some number of uninsured poor Missouri citizens. It would be the height of moral obtuseness if some state bureaucrat brushed off this moral criticism with the claim that an allocation decision had been made, not a rationing decision, and that was the end of the discussion.

The very general conclusion I wish to draw at this point is that objective approaches to health care cost containment (practice guidelines, technology assessment, cost-effectiveness research, costbenefit analysis, health planning strategies that would control the number of ICU beds or transplant centers or artificial hearts produced) are all legitimate approaches to cost containment that ultimately rest upon moral premises. My further claim is that these moral premises need to be made explicit so that they can be publicly assessed through a democratic consensus mechanism.

${ }^{36}$ See Steven H. Miles, Informed Demand for "Non-Beneficial" Medical Treatment, 325 NEW ENG. J. MED. 512, 513 (1991).

${ }^{37}$ See Joan H. Lewis, How Much Care Can We Afford?: Basic Treatment for Many vs. Costly Measures for a Few, WASH. POST, July 9, 1991, at Z6.

${ }^{38}$ See Rick Curtis, The Role of State Governments in Assuring Access to Care, 23 INQUIRY 277, 279 tbl. 1 (1986). 


\section{A Morally IneXcusable Tragic CHOICE: INVISIBLE RATIONING}

There is no adequate moral or political justification for implicit or invisible rationing. Rawls points out that a core element of our shared conception of justice is the "publicity condition," which says in effect that when we have fair policies and practices, nothing needs to be hidden. ${ }^{39}$ Aaron and Schwartz provide us with a convenient example of invisible rationing. In Britain, dialysis is provided to only about thirty-five percent of the patients who could medically benefit from the procedure. In general, neither individuals over age sixty-five, nor individuals over age fifty-five who have a complicating medical condition, such as diabetes or heart disease in addition to renal failure, are offered dialysis. ${ }^{40}$ But there are no formally promulgated rules. Physicians recognize that there are only so many dialysis slots because of limited government budgets. Hence, informal understandings have arisen among physicians regarding patients who are "good" candidates for dialysis. Patients who are denied access to dialysis are not told they are being denied dialysis for some reason. Instead, they are simply told that nothing more can be done medically, which leaves them with the belief that they have a medically untreatable condition rather than one that has been judged socially and economically unworthy of treatment. This is not a morally tolerable state of affairs. As Ronald Bayer observes, invisible rationing decisions are "beyond the pale of public scrutiny or accountability," which means that criteria may be used that are "capricious, unreasonable, or dangerous." 41

Calabresi and Bobbitt are among those who defend the moral legitimacy of invisible rationing mechanisms. Their basic claim is that society is becoming more frequently ensnared in "tragic choice" situations. These are situations involving a fundamental conflict of societal values such that choosing and affirming one value necessitates violating the other. ${ }^{42}$ For them any choice made in these circumstances is profoundly morally flawed. Hence, in the face of

${ }^{39}$ See Rawls, Kantian Constructivism, supra note 3, at 535-54.

40 See Henry J. Aaron \& William B. Schwartz, The Painful Prescription: RATIONING HoSPITAL CARE 28, 34-35 (1984). For a thorough discussion of the history, politics, economics and ethics of the end-stage renal dialysis program in Great Britain, see Thomas HalPER, THE Misfortunes OF OTHERS: END-STAGe Renal DISEASE IN THE UNITED KINGDOM (1989).

41 Ronald Bayer et al., The Care of the Terminally Ill: Morality and Economics, 309 NEW ENG. J. MED. 1490, 1490-91 (1983).

42 See CALABRESI \& BOBBITT, supra note 26 , at $18-19$. 
these tragic choices, the fundamental moral problem is to "preserve the moral foundations of social collaboration." 43 And if any choice made threatens the moral foundations of society, then that provides a moral warrant for making it invisibly, in a way that escapes public scrutiny. ${ }^{44}$ In short, if Calabresi and Bobbitt are

43 Id. at 18.

44 In my judgment Calabresi and Bobbitt flip-flop between descriptive (sociological) ethics and normative (philosophic) ethics. There are numerous passages in the early part of their book that suggest that their primary intent is to describe these tragic choices as they emerge in various political/economic circumstances, and then to describe the ways in which societies use various social mechanisms to hide or evade or cope with these tragic choices. In other words, they make no judgment at all about the rightness or wrongness of these coping strategies. An illustrative passage supporting this point reads: "Examples too often are taken to imply prescription or solution, and we have few prescriptions and no solutions." Id. at 17.

But they also make clearly prescriptive judgments, such as: " $[\mathrm{H}]$ onesty must be protected from those allocation methods which taint it . . . [H]onesty] is more than an instrument, it is measurement itself, for it is honesty which allows us to see clearly, and occasionally appreciate, the ways, some subtle and some not honest, by which societies must cope." Id. at 26. This certainly sounds like a strong prescriptive endorsement of honesty as a basic societal value. Indeed, we can see their writing of this book as an affirmation of this value. But they also write: "They [honesty and openness] are no more absolute than the other values [sanctity of life and equality of all men]." Id. at 50. This too is a prescriptive statement, though it suggests honesty and openness may be traded off in order to protect other basic values. Again, they write:

Honesty is also ambivalent. It has the remarkable quality that it is capable of being abandoned with regard to some questions without being destroyed everywhere. Thus it can often be of service to the tragic choice by being neglected-indeed the usefulness of some allocation methods depends almost entirely on the charade that they serve the purposes they say they do.

Id. at 24.

In their concluding chapter Calabresi and Bobbitt write: "The answer is, we have come to think, that a society may limit the destructive impact of tragic choices by choosing to mix [allocation/rationing] approaches over time. Endangered values are reaffirmed. The ultimate cost to other values is not immediately borne. ${ }^{n}$ Id. at 196. And:

Since the values endangered by any given [allocation/ rationing] approach vary, a society which wishes to reject none of them can, by moving, with desperate grace, from one approach to another, reaffirm the most threatened basic value and thereby seek to assure that its function as an underpinning of the society is not permanently lost.

Id. at 198. This certainly appears to be an endorsement of implicit rationing approaches and the compromise of social honesty that is integral to such approaches. This is clearly how Steven Rhoads approvingly reads Tragic Choices. He writes that he would "tolerate a little dissembling in this area [choosing which lives to save at what price]" rather than publicly admit that human life is not priceless. Steven E. Rhoads, How Much Should We Spend to Save a Life?, in VAluing LIFE: PUBlic POLICY Dilemmas 285, 305 (Steven E. Rhoads ed., 1980). Again Calabresi and Bobbitt can follow their own recommendation and move "with desperate grace" to affirm that 
right, then the argument I would make for a democratic consensus approach to health care rationing is fundamentally wrong. However, I will argue that their account is open to criticism.

Invisible rationing mechanisms certainly seem to violate our societal sense of honesty. Calabresi and Bobbitt clearly want to maintain that honesty and openness, which are essential structural values in our society. ${ }^{45}$ Still, if we are totally honest, then we will have visible tragic choices, "an exposed inegalitarianism" and "exposed decisions against life." choices are not amenable to rational moral resolution. ${ }^{47}$ All such efforts will be tragically flawed. The best that any society can hope is to "cope" with these tragic choices, and invisible rationing mechanisms are among these coping devices. These coping devices have moral utility because they protect the bonds of society from the otherwise corrosive effects of exposed tragic choices, but they are never fully morally justified because they violate the basic norms of honesty.

Two critical comments are in order. First, why did Calabresi and Bobbitt write their book? Their reply is that their effort would "allow us, as citizens, to accept responsibility for tragic choices decided in our names," and enable us to better see ourselves "acting

honesty and openness are basic societal values that they unequivocally endorse. But then we have Professor Brian Barry's observation in his review of Tragic Choices:

[T] he book gives the impression that this is what it is about: not how societies cope with tragic choices but how they attempt to deny their existence. It is not very easy to show this by selective quotation, but I think that anyone who has read the book is likely to have come away from it with the feeling that the book is about fudging rather than facing policy choices in life and death cases.

Brian Barry, Tragic Choices, 94 ETrircs 303, 308 (1984) (book review). I completely concur with this conclusion.

${ }^{45}$ See CALABRESI \& BOBBIT, supra note 26 , at 50.

46 Id. at 37 .

${ }^{47}$ To be sure, Calabresi and Bobbitt say that societies attempt to use rational means, such as markets and political allocation mechanisms, to address these deep and tragic value conflicts. The result of these efforts is that "the tragic choice is transformed into an allocation which does not appear to implicate moral contradictions. Morally debasing outcomes are averted. But unless the values held in tension have changed, the illusion that denies their conflict gives way and the transformation will have only been a postponement." Id. at 18 (emphasis added). They go on to quote several writers on tragedy who speak of "insuperable moral difficulty," "the inevitability of paradox," and "unresolved tensions and ambiguities," all of which suggests very clearly that rational resolution of these tragic choices is not possible in their judgment. Id. at 18-19. 
to save ultimate values from necessary desolation. ${ }^{n 48}$ Does this mean they really want all of $u s$ to have a clear reflective awareness of these tragic choices and of the invisible decision mechanisms we employ to mask these choices? If so, what is the point of invisible decision mechanisms? From whom are we seeking to hide some tragic truth? From ourselves? Then why be reflective about the matter? From someone else? Who might that be? Here we have a serious moral problem.

The passages just quoted evoke images of a tragic moral hero, committed to ennobling ideals, but knowing that they are destined to be defeated. Does this mean Calabresi and Bobbitt want every post-fifty-five-year old working class Briton in renal failure to understand and accept the denial of dialysis to himself because the government chose to limit resources for dialysis? ${ }^{49}$ This would be heroic. But, if this heroism were possible, there would be no need for invisible rationing mechanisms. By way of contrast, British physicians understand how things are with respect to dialysis. Nothing is invisible to them. They have an opportunity to be moral heroes. So, how many fifty-seven year-old British physicians in renal failure, complicated by diabetes, just accept their tragic fate? The point is that it is too easy to rationalize the imposition of injustice on others under the noble guise of necessary tragic choices. Further, we do them a double injustice when we render this imposition invisible under the guise of protecting from corrosion the moral bonds that link us with them in a moral community. At the very least we are guilty of undermining the possibility of a critical moral conversation that we (societal powerholders) would find both embarrassing and pointless since we contend the moral tragedy is inescapable anyway. ${ }^{50}$

A major moral problem, then, with these invisible rationing mechanisms is that they tend to create an invisible class of "others," who may be victims of injustice without knowing that they have

48 Id. at 27.

${ }^{49}$ See supra notes $40 \& 44$.

50 Thomas Halper supports this point nicely:

Of course, this political role [of the nephrologist in Great Britain as allocative agent for the state] is nowhere explicitly acknowledged. This is not a trivial matter, for it helps to ensure that the vast majority of patients and their families-and even a few physicians themselves-will be blind to the true nature of the situation. Thus blind, they will mistake political judgments for medical ones and be far more likely to acquiesce.

HALPER, supra note 40, at 133; see also id. at 128-40. 
been victimized. If that is what is really meant when we speak of the need to "preserve the moral foundations of social collaboration," 51 then it is not difficult to imagine why these "others" would not wish to be part of such a moral community. The virtue of a democratic consensus approach to health care rationing, even in a nonideal form, is that it avoids creating these "others" who can be victimized within a "moral" community. There are no "others" because all are part of the social conversation that generates the rationing principles and protocols that will apply to all.

This brings me to my second moral criticism. The language of "tragic choices" tends to insulate the consciences of societal decisionmakers from critical moral self-reflection, for the implication of the phrase is that the injustices are necessary and inescapable. I will grant for the sake of argument that some mix of injustices really is inescapable as far as health care rationing is concerned, that no matter what we do in articulating some comprehensive mix of rationing principles and protocols, some number of individuals will be denied opportunities for extra life-years or will have to endure some extra death-risks for which there will be no uniquely adequate moral justification. That is, these individuals can reasonably claim they were treated unjustly. But what follows from this? Surely we ought to make a distinction between a completely random, episodic distribution of injustices in a society and a patterned distribution of injustices that might be a product of decentralized decisionmaking mechanisms, a pattern that might not even be visible to the dispersed decisionmakers, but that might nevertheless reflect certain deep-seated social biases. A random pattern of necessary instances of injustice would be morally tolerable in a world where perfect justice was not realizable. But a patterned distribution of injustices, especially one that reflects other societal biases, is a rather different matter and should not be immune from moral criticism. Yet the language of tragic choices totally obscures this distinction and would prevent societal moral self-criticism.

In summary, the notion of tragic choices licenses a morally laissez faire attitude. Such a state of affairs hardly contributes to preserving "the moral foundations of social collaboration." Honesty is undermined. Fairness and various individual rights are threatened. And the moral and political autonomy of individuals is

${ }^{51}$ CALABRESI \& BOBBITT, supra note 26, at 18. 
seriously compromised because others will make decisions that might profoundly affect their lives without their having the opportunity to participate in the making of those decisions. Again, what this analysis suggests is that a democratic consensus approach to health care rationing is more likely to yield results that are just, in part, because they are freely self-imposed.

\section{JUST HEALTH CARE RATIONING: THE NEED FOR DEMOCRATIC CONSENSUS}

If we can create public social processes through which rationing decisions become something that we collectively impose upon ourselves, then we will have rationing decisions that will have at least prima facie moral legitimacy. The model I defend is the informed democratic consensus model. "Informed" means that the consensus is a product of rational deliberation, both moral and scientific. The best available scientific information shapes the conversation as well as the best methods of critical moral reflection. Put negatively, the consensus is not a product of random polling of haphazardly held public opinion and prevailing biases. Next, "democratic" is intended to convey the idea that this is a public conversation among free and equal individuals. The basic model I have in mind here is that described by Bruce Ackerman in Social Justice in the Liberal State. ${ }^{52}$ Participants in the conversation are committed to rationality, liberal neutrality, and undominated equality. ${ }^{53}$ Finally, I wish to follow Bruce Jennings in advocating a "morally thick" conception of consensus, one that is not merely a contingent historical fact with no rational or justificatory power. Rather, consensus has moral force when it "emerges out of deliberations that are honest, factually well-informed, rule-governed, and fair," and when "there are no widely recognized, independent grounds for establishing the moral truth," and "there are no single, authoritative judges or decisionmakers available." ${ }^{54}$ This is essentially the situation that we find ourselves in with respect to the issue of justice and health care rationing. That is, we have several

52 See Bruce A. Ackerman, Social Justice in the Liberal State (1980).

${ }^{53} \mathrm{See}$ id. at 3-30. James Fishkin endorses essentially the same three "democratic conditions" as Ackerman, though he labels them political equality, nontyranny, and deliberation. See JAMES S. FISHKIN, DEMOCRACY AND DELIBERATION: NEw DIREcTIONS FOR DEMOCRATIC REFORM 29-41 (1991).

54 Bruce Jennings, Possibilities of Consensus: Toward Democratic Moral Discourse, 16 J. MED. \& PHIL. 447, 451 (1991). 
broad conceptions of justice in our society, but we have failed to articulate a coherent conception of "health care justice," which should be thought of as a fairly distinctive "sphere of justice."

We need to explain a bit more about the democratic consensus model and the reasons why it is morally preferable to any alternative approach to health care rationing. Though this is highly simplified, the alternative approaches would seem to be: (1) rationing by markets/ability to pay; (2) rationing at the bedside by individual physicians; (3) rationing by bureaucrats or legislators or health care administrators.

The moral virtue of markets is that they are impersonal or impartial; markets do not make invidious discriminations. They reflect rather than correct broader societal inequities and discriminations, however, and in that respect they are not morally neutral distributional instruments. Moreover, markets fail to distinguish between health desires (tummy tucks) and health needs (cancer chemotherapy), which is a moral failing, if we believe that health needs ought to be met before health desires. Markets are also supposed to be paradigmatically efficient. Although this is generally true outside of health care, health care markets and market

55 See Michael Walzer, Spheres of Justice: A Defense of PluRalism and EQUALITY 3-30 (1983). There are essentially two reasons why the distribution of health care should be thought of as a distinct sphere of justice. First; from a moral perspective, health care is usually something individuals need rather than simply desire, and health care today often makes the difference between life and death, or at least between a substantially impaired life and a highly functional life. This seems to make health care a distinct kind of social good. Second, from an economic perspective, we have made health care a distinct kind of good through the insurance mechanism. Patients do not purchase health services in the way other consumer goods are purchased, that is, by reference to relative strength of competing preferences (for patients typically have health needs, not health preferences), or by reference to their own individual willingness or ability to pay for specific health services. Instead, there is a common pool of funds that patients may draw upon to purchase needed health services, and the rules for judging what counts as a legitimate draw on those funds are typically nebulous. Specifically, if a physician says that a health service is needed, then that will count as a legitimate draw on those funds. The problem, however, is that physicians usually have an economic interest and a professional interest in maximal well-being for an individual patient that will result in a constantly expanding definition of what counts as a health need, such that very marginal benefits will be sought at very great cost-not directly to that individual, but to society. This represents a real harm, often an injustice, albeit one that is usually effectively hidden from social scrutiny, as in the excess cancer death rate noted earlier among the uninsured poor. See supra note 16 and accompanying text. In brief, the moral challenge within the sphere of health care justice is to distinguish unfortunate health outcomes (to which no moral blame attaches) from unjust outcomes (which are blameworthy and in need of reform). 
competition contribute to extremely wasteful inefficiencies because of the insurance mechanism. ${ }^{56}$ Thus, markets in health care fail to control escalating health costs, fail to establish morally defensible priorities for health spending, and tend to generate wasteful and inequitable inefficiencies of their own.

Physicians might also serve as front-line rationers. The general idea is that the likelihood of significant health benefit is a morally defensible basis for establishing health priorities and making rationing decisions. Physicians are the only ones in our society who have the professional expertise and knowledge of individual patient circumstances to make such judgments well. To assist physicians in making these judgments knowledgeably we need to invest in a major effort aimed at technology assessment and the development of practice guidelines that are based on sound clinical research. However, there is a twofold difficulty with this approach. First, whether we are talking about practice guidelines, cost-benefit analyses, cost-effectiveness analyses, or technology assessment, the judgment must ultimately be made that some therapeutic or diagnostic intervention does or does not produce enough benefit (from some societal point of view) to warrant the cost. That is, at bottom there is a value judgment that needs to be made, and no amount of empirical clinical research will yield that value judgment. From whence comes that value? In a liberal democratic society patients may legitimately ask why they should accept that value when it is not their value. If they want that $10 \%$ chance of an extra year or two of life that is represented by that autologous bone marrow transplant for breast cancer that will cost their insurance company $\$ 150,000$, then why should they be denied it because "society" thinks that is a bad buy? Secondly, why should they be denied it by their physician, who is supposed to be a loyal and uncompromised advocate of her patients' best medical interests? ${ }^{57}$

The third alternative approach to health care rationing (relying upon bureaucratically or legislatively generated rationing protocols) is supposed to extricate physicians from the above moral dilemma.

${ }^{56}$ One such example is the proliferation of Magnetic Resonance Imaging Centers all over downtown Chicago, like the proverbial dandelions after a spring rain. See Michael L. Millenson, A Conflict of Image in Health Care, CHI. TRIB., Feb. 23, 1992, § 7, at 1 . He notes that in Florida excess MRI scans cost the insurance pool $\$ 185$ million in 1991 alone.

${ }^{57}$ See Norman G. Levinsky, The Doctor's Master, 311 NEw ENG. J. MED. 1573, 1573 (1984) (arguing that "physicians are required to do everything that they believe may benefit each patient without regard to costs or other societal considerations"). 
The general idea is that these rationing protocols come from some authoritative "outside" source that imposes these protocols upon the physician so that the physician has no real choice to make, and hence, is supposed to be morally blameless. However, how could a morally conscientious doctor allow herself to be used like that? Furthermore, rationing protocols that are bureaucratically generated can never be fine-grained enough to apply without judgment or adjustment to the very unique clinical circumstances of individual patients, which is to say that clinicians cannot really escape moral (or medical) responsibility for interpreting and applying these rationing protocols to individual patients. ${ }^{58}$ Someone might argue that rationing protocols generated in the public sector have some moral legitimacy because the values they reflect are public values or public interests. But this would be very naive, politically speaking, for the reality seems to be that competing interest groups significantly shape the outcomes of the legislative process, and hence, the values of more powerful health interest groups would be reflected in any rationing protocols. If this is true, then what is the moral justification for physicians being the agents of these more powerful interest groups against the interests of their patients?

To return to the real world (of bureaucrats and legislators), actual examples of rationing protocols are very hard to find, which is why Oregon has gotten so much media attention. Explicit rationing protocols are extremely divisive and controversial, which is why they are politically unattractive. In the real world, bureaucrats and legislators use budgets as rationing tools. In the Medicare program, DRGs are (suggested) micro-budgets. What any specific DRG will mean for any particular Medicare patient in the way of rationing decisions will be infinitely variegated. It may depend upon a value judgment that a physician makes about a patient with this much dementia, or who has often been noncompliant, or who is obnoxious. Or it may depend upon the relative political power of this physician at this institution, the general idea being that a physician who is a major referrer to this hospital may exceed DRG "limits" with greater impunity than a physician who is an average referrer. Or it may depend upon the overall patient base and economic strength of the institution, the general idea being that institutions with a $60 \%$ Medicare/Medicaid population will be compelled to make more rationing decisions and more stringent

${ }^{58}$ See E. HaAvi Morreim, Balancing ACt: THE NEW MEdical Ethics of MEDICINE'S NEW ECONOMICS 45-70 (1991). 
rationing decisions than an institution with $20 \%$ Medicare patients and virtually no Medicaid patients. In such a situation there is no overall consistency (even within an institution); there is enormous opportunity for arbitrary and discriminatory judgments for which no one will be held accountable; there is no assured rational relationship between medical need or likelihood of medical benefit and the diagnostic or therapeutic care that is actually given; there is no connection at all between the values that drive these rationing decisions and the values of the patients whose welfare will be most affected by these decisions; and finally, there is a tendency for bureaucratic rationing to perpetuate inefficient processes of cost shifting rather than effective cost containment. As Eddy has observed, the ultimate cost shift is to future generations, ${ }^{59}$ who are unable to defend their interests through the political process. An outcome like this has nothing to recommend it, either morally or politically.

This brings us back to an informed democratic consensus approach to health care rationing. If we want effective cost containment/rationing in health care (no cost-shifting), then we have to find a way to link cost and value through patients since they have the most to gain or lose, wealthwise (as taxpayers/premium payers) and healthwise (as patients). And if we want a fair approach to health care cost containment and rationing, then rationing protocols will have to be public or explicit, rationally justifiable, autonomously imposed, and impartially generated and applied. These are all conditions that can be met by the informed democratic consensus approach.

Both David Eddy and Norman Daniels have identified the essential moral insight that makes the informed democratic consensus approach both fair and feasible. ${ }^{60}$ It is that any fair approach to health care rationing must be a product of patient choice, freely and rationally self-imposed, not simply at an instant in time, but over the course of a life, and not simply from the point of view of my actual self, but from the point of view of an indefinitely large number of possible healthy/unhealthy selves I might

${ }^{59}$ See David M. Eddy, The Individual vs. Society: Resolving the Conflict, 265 JAMA 2399, 2406 (1991).

60 See David M. Eddy, Rationing by Patient Choice, 265 JAMA 105, 107 (1991); NORMAN DANIELS, AM I MY PARENTS' KEEPER?: AN ESSAY ON JUSTICE BETWEEN THE YOUNG AND THE OLD 40-65 (1988) (introducing his prudential lifespan account). 
become which, we shall see, will overlap in complex ways with numerous other selves that comprise our society.

Eddy argues that patients must ask themselves the following kind of questions: "Is it worth $\$ 900$ to perform magnetic resonance imaging for a patient with a headache if there is a $1 \%$ chance of finding a treatable tumor? . . Is $\$ 10,000$ too much for a treatment that reduces one-year mortality after a heart attack by $1 \%$ ? $^{n 1}$ Of course, if it is someone else's money that I am spending, and if I am the patient terrified of dying who has had the heart attack, then no amount of money is too much for however slight a medical benefit. If that is the conclusion we reach, then fairness and efficiency have both been defeated. So Eddy wants us to think about these kinds of questions from the point of "Patients," (with a capital "P") that includes both the well and the ill. This yields a suitably impartial perspective, though it now seems like a very distant and depersonalized perspective, not something that I would initially recognize as representing my own autonomous choices. Eddy, however, argues this is more appearance than reality.

Eddy asks us to consider the case of a fifty-year-old woman with metastatic breast cancer. Should society offer her an autologous bone marrow transplant (ABMT) at a cost of $\$ 150,000$ if at best her chances of a cure are $5 \%$ ? That same $\$ 150,000$ would buy ten years of mammograms for 150 women between age fifty and sixty, the result being that seven of these women will be saved from death from breast cancer. ${ }^{62}$ What Eddy concludes is that the conflict represented by this scenario "is not between individuals, but within each individual." ${ }^{33}$ He goes on to observe that "individual patients and society are not distinct entities. Rather, they represent the different positions that each of us will be in at various times in our lives." ${ }^{\text {If }}$ we have only $\$ 150,000$ to spend, and if we spend it all trying to save this patient after she has gotten this disease (believing thereby that we are doing everything for her), then "everything will not have been done for that person if you consider that person's entire lifetime."65 For that woman could well be one of those seven women whose life would have been saved by a screening mammogram if the $\$ 150,000$ had been available for that purpose.

61 Eddy, supra note 60, at 107.

62 See David M. Eddy, The Individual vs. Sociely: Is There a Conflict?, 265 JAMA $1446,1449-50$ (1991).

${ }^{63} \mathrm{Id}$. at 1449.

${ }^{64} I d$. at 1450 (emphasis added).

${ }^{65} \mathrm{Id}$. 
Note that it could have been the case ten years ago that this woman was part of a pool of one thousand women in a large corporation who, in order to control their escalating health insurance premiums, agreed among themselves that it was a better buy, all things considered, for each and every member of that group to cover screening mammograms instead of ABMT. This is Eddy's Patient. And this is also a small scale version of what the informed democratic consensus approach to health rationing is all about. She will understand that by making this choice there is a chance that even with the screening mammogram her cancer will be missed or detected too late, though there is a significantly greater chance that her cancer will be detected and her life will be saved through this screening program. Still, if it is not detected, then she will be denied the small chance at life represented by ABMT. The morally important point is that if this happens, then she will be unfortunate, but she will not have been treated unjustly. She will not have been denied ABMT by some stingy and uncaring administrator, but by herself-a free, informed, rational, impartial self ${ }^{66}$ choosing in accord with her own values, which, significantly, include a commitment to justice, both fair procedures and fair rationing protocols agreed to by all.

Note that over a ten-year period it is likely several women in this group will have breast cancer and will have died because they will not have been given access to ABMT, which means this woman will have economically benefitted from those savings. If she herself now has end-stage breast cancer, and if she pleads and manipulates and threatens legal action to secure ABMT for herself, and if that administrator gives in to her entreaties, then both are guilty of injustice. Hadorn, among others, has observed that this sort of

${ }^{66}$ I want to make clear that the "impartial self" to which I refer is not a mere heuristic device (like Rawls's well-known "veil of ignorance," see infra note 96 and accompanying text). Rather, it must be a real world possibility if we are to see just policies and practices sustained in our society. I will concede that no one is ever perfectly informed, perfectly rational or perfectly impartial. That, however, is not the issue. The issue is whether we can be informed enough, rational enough, and impartial enough to create and accept specific rationing protocols for our future selves. This is really asking whether we are capable of having an effective sense of justice. Though there may be many individuals who are lacking this capacity, our society as a whole sustains complex social practices, such as our system of criminal and civil justice, which would not be possible unless there were a widely inculcated sense of justice that was effective enough. Explicit rationing protocols reinforce this effective sense of justice, in part, because the very explicitness of the process allows apparent injustices to be publicly challenged and justified. 
explicit rationing is very difficult to implement in practice because society is committed to a "duty to rescue" ${ }^{\$ 7}$ when there are such visible identifiable patients who are in imminent peril and for whom there is something we could do that might save their life. But if the analysis given here is correct, and if our rationing protocols are products of an informed democratic consensus, then any such alleged "duty to rescue" is morally specious at best and morally pernicious at worst because a just consensus about health care rationing will be violated. This same analysis applies to any physician who, out of a misguided sense of loyalty or compassion to this patient before him, acquiesces to the pleas of this patient, for in truth he will be disloyal to and lacking in compassion for that larger Patient with whom this patient is also identified.

There are two further questions we need to answer by way of outlining this model. First, who are the individuals who would be seeking to achieve this democratic consensus on health care rationing, and how would they be organized? Second, what precisely is it that they would be discussing, and what would be the value standards they would use to achieve consensus?

I imagine that there would be fifty citizen/patients who would make up a district health council, one per congressional district. In some broad sense these individuals would be "representative" of that district, but they would not represent any very specific interest in that district, such as the heart disease lobby, or the mentally retarded, or for-profit imaging centers. ${ }^{68}$ They would be volunteering to carry out a very serious social responsibility. At the moment I am inclined to think that all providers of health services (clinicians, administrators, insurers) would be denied membership on these councils, though they would have ample opportunity to offer their expert advice to these councils. Each of these district councils would elect one of their members to serve in a national health congress. They would be instructed to elect that person whom they judged to be most judicious and fair-minded. This national health congress would establish the issue agenda for all the district councils. What would emerge from democratic deliberation at the district level would be a local consensus that would provide

67 David C. Hadorn, Setting Health Care Priorities in Oregon: Cost-Effectiveness Meets the Rule of Rescue, 265 JAMA 2218, 2219 (1991).

${ }^{68}$ I realize. that I am ignoring vast and important debates among political philosophers and political scientists about what "representation" might mean in these circumstances, both conceptually and practically. Space does not allow addressing that issue. 
the partially refined material for a national consensus. The local consensus would include a detailed statement of the reasoning that supported that consensus.

The Eddy example we discussed above is a very simple example of what the informed democratic consensus approach means in practice. That is, the substance of their discussion would involve priority setting among health services, articulating very specific rationing protocols, and articulating considered judgments of health care justice that captured the values that were governing the priority setting/rationing process. In the real world it seems these councils would have to discuss literally thousands of diseases and thousands more therapeutic options to which would be attached a wide range of probabilities of success. This sounds like an impossible task. But I imagine it is more manageable than we might first realize. After all, there would be a very large core of health services for which we would have a very high degree of consensus that the value of the services was worth the costs to Patients. Some of those judgments would change in the light of future clinical research and advances in medical technology. But $I$ assume that most of the serious public debate would be around the fringes of that core where the judgment was that the benefits were marginal to very marginal and the costs very high. This will not be an easy debate. What should a just and caring society decide about the level of medical support for a 600-gram premature infant? And what kind of decisions should a just and caring society make about whether to fund publicly, as part of a national health program, various treatments for infertility? And should a just and caring society pay for a hypertension medication that costs $\$ 120$ per month rather than one that costs fifteen dollars per month but that is associated with impotence?

I now need to make explicit what has been a major assumption behind this democratic consensus model: all in our society would be part of a single comprehensive health plan. There can be no Medicare or Medicaid or private health insurance companies. Pluralism is thought to be an essential feature of our political system in all policy areas. But in health care pluralism with respect to health plans results in enormous inefficiencies and intolerable inequities. 
Ezekiel Emanuel has recently argued for an opposite point of view. ${ }^{69}$ He would allow for thousands of community health plans in the United States, each with its distinctive value orientation, philosophy of health, and philosophy of health care rationing. ${ }^{70}$ He would use a voucher mechanism that would allow individuals to choose among plans. ${ }^{71}$ Obviously, however, that voucher could not have a uniform or average value since tens of millions of individuals would have pre-existing medical conditions that would generate medical costs well above the annual value of that voucher, the result being that such individuals would not be wanted by any of these health plans. The alternative would be to set the value of the voucher to the anticipated health status of that individual for that year, which could be an expensive bureaucratic nightmare. I have provided a very detailed critique of such pluralistic approaches to national health insurance elsewhere, so I will not repeat those arguments here. ${ }^{72}$

In summary, I will simply point out that Eddy's Patient can be used most effectively as a tool of moral analysis and democratic deliberation and consensus-building only if all of us can identify with that Patient, only if all of us must live and die with the same rationing protocols. That Patient is what forces us to make tradeoffs between cost and value within ourselves rather than seizing the marginal benefits for ourselves and imposing the costs on others. Again, Norman Daniels has pointed out most clearly why physicians cannot in our current system carry out any rationing protocols in good conscience. ${ }^{73}$ We do not have a closed system. A physician who denies his Medicare patients extra hospital days does not know that the money he saved will be used to fund more important health needs of the elderly. For all he knows, those dollars can be used to bail out failed savings and loan associations. But in the universal closed system that we envision with explicit health priorities and

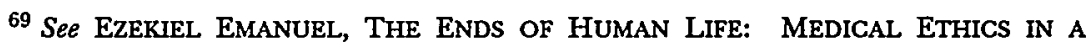
LIBERAL POLITY (1991).

${ }^{70}$ See id. at $178-244$.

71 See id. at 185-92.

72 See Leonard M. Fleck, How Just Must We Be?, in BIOMEDICAL ETHICS REviEwS 1990, at 131 (James M. Humber \& Robert F. Almeder eds., 1991). The focus of my criticism in this article is the Enthoven-Kronick pluralistic competitive approach to national health insurance. See Alain Enthoven \& Richard Kronick, A Consumer-Choice Health Plan for the 1990s: Universal Health Insurance in a System Designed to Promote Quality and Economy, 320 NEW ENG. J. MED. 29-37, 94-101 (1989) (two-part article).

73 See Norman Daniels, Why Saying No to Patients in the United States Is So Hard, 314 NEW ENG. J. MED. 1380, 1382 (1986). 
rationing protocols democratically endorsed, a physician can in good conscience implement those rationing protocols because the savings will be recaptured for higher priority health needs, and those protocols and priorities will have been endorsed by that patient before her. ${ }^{74}$

At present, Oregon represents the only real full-scale model of what rationing by democratic consensus might look like. It is very far from being a perfect embodiment of what I have in mind, but it is more morally defensible as a model than most of its critics are willing to admit. Oregon's radical policy initiative is usually described as a "Medicaid rationing experiment." This is a half-truth that is terribly misleading. Oregon had essentially two policy objectives. One was to control escalating health costs to the state budget; the other was to find a way of providing health insurance for all in the state so that everyone would have assured access to needed health care. A package of three bills was designed to achieve these objectives. One bill raised Medicaid coverage from fifty-eight percent of the poverty level to $100 \% .^{75}$ Another bill mandated that all employers provide for all workers at twenty hours per week or more a health insurance benefit package at least equal to the Medicaid package or pay eight percent of payroll as a health tax. ${ }^{76}$ The third bill would create a state insurance fund that would provide subsidized insurance for those now denied health insurance. ${ }^{77}$

In order to control costs to the state for Medicaid a priority setting (rationing) scheme was devised. The original version tried to prioritize 1600 medical interventions with some very unsettling results. ${ }^{78} \mathrm{~A}$ more recent version identified 709 condition-treat-

74 Note that the integrity of this democratic consensus-building process needs to be protected from interest group politics as usual. In my judgment all such interests are extraneous to the interests of Eddy's Patient, and represent an incursion of the politics of power into what is supposed to be the arena of rational political deliberation. Hence, I imagine that the role of the U.S. Congress would be to set a national health budget, but Congress itself would have nothing to do with establishing, ratifying, or modifying health priorities or rationing protocols. All of this would be the sole responsibility of the national health congress. Oregon made a similar separation of responsibility between its Health Commissioners and the state legislature. In my judgment this was both prudent and necessary.

75 See S. 27, 65th Leg., Reg. Sess., 1989 OR. LAws 836.

${ }^{76}$ See S. 935, 65th Leg., Reg. Sess., 1989 OR. Laws 381.

77 See S. 534, 65th Leg., Reg. Sess., 1989 OR. LAws 838.

${ }^{78}$ See, e.g., David C. Hadorn, The Oregon Priority-Setting Exercise: Quality of Life and Public Policy, Hastings CenTER ReP., May-June 1991, at supp. 11, 11 (noting that the original version prioritized office visits for minor problems over certain life-saving 
ment pairs that have been ranked in seventeen categories. ${ }^{79}$ Those medical interventions that are most effective, that achieve substantial medical good at reasonable cost, and that save or prolong lives of reasonable quality rank higher on that priority list. Oregon will fund as far down that list as the state budget permits. The expectation at this writing is that funding will cover the first 587 services. $^{80}$

Oregon deserves credit because this entire process was carried out with a clear sensitivity to the relevant moral values. ${ }^{81}$ It was not just an exercise in economics, statistics, and organizational behavior. There was an explicit commitment to universal basic health care for all. The state made a commitment to a process of decisionmaking that was fully public and visible, and rejected the irrationalities and injustices that are typical of virtually every state Medicaid program wherein individuals would be thrown off Medicaid rolls in order to help balance the state budget with no attention paid at all to their current health status or health needs. Efficiency considerations could now be harnessed to yield greater equity-the more wasteful, marginally beneficial medical interventions that could be identified, the more resources that would be available for relatively more beneficial care for more of the medically needy.

A serious effort was made to involve as large a segment as possible of the public in the process so that it could be justifiably maintained that this rationing approach was self-imposed and democratically determined. About forty-seven forums were held and somewhere in excess of 1000 people participated. ${ }^{82}$ But, as Fox and Leichter note, the vast majority of those in attendance were health care professionals, ${ }^{83}$ hardly a representative cross-section of citizens of Oregon. There was also a random telephone survey of 1000 Oregonians. ${ }^{84}$ At best, it is fair to say that the Oregon

surgeries).

${ }_{79}$ See id. at supp. 11-12. For a more detailed description of Oregon's efforts, see Charles J. Dougherty, Setting Health Care Priorities: Oregon's Next Steps, Hastings CENTER REP., May-June 1991, at supp. 1, and Hadorn, supra note 67, at 2220-21.

${ }^{80}$ See David M. Eddy, Oregon's Plan: Should It Be Approved?, 266 JAMA 2439, 2439 (1991).

81 See, e.g., John Kitzhaber, Rationing Health Care: The Oregon Model, THE CENTER REPORT, Winter/Spring 1990, at 3 (discussing the Oregon plan in some detail).

${ }^{82}$ See Daniel M. Fox \& Howard M. Leichter, Rationing Care in Oregon: The New Accountability, Health AfF., Summer 1991, at 7, 21.

${ }^{83}$ See id.

${ }^{84}$ See id. 
experience is an example of modest democracy and modest participation. Still, it is a start. The real question for us is whether this is a damning indictment of the democratic consensus approach. In my judgment it is not.

The most serious and oft repeated criticism of this process was that it represented exploitation of the Medicaid poor. ${ }^{85}$ The poor were to be the guinea pigs for a social experiment in health care rationing while the middle class observed from the safety of their Blue Cross plans. However, to make these criticisms stick two things would have to be shown: (1) the poor as a class were less well off under this experimental program than in the old Medicaid; and (2) the poor themselves would not autonomously choose to be part of this program. As I have argued elsewhere, neither of these claims are true. ${ }^{86}$ Oregon is putting at least 30 million more dollars into Medicaid, and forty-two percent more of the poor will be eligible for Medicaid. ${ }^{87}$ The total package of services for each poor person will be less robust, but the services they will be denied will be (for the most part) marginally beneficial, noncostworthy services. But would a poor person rationally and freely accept these trade-offs? Yes! There is considerable turnover below the poverty level-about twenty-five percent per year. ${ }^{88}$ That is, the very poor get part-time jobs that make them ineligible for Oregon Medicaid services, which are provided to only fifty-eight percent of those below the federal poverty level. Not only do they lose Medicaid, but they cannot afford private health insurance, which means no assured access to any health care at all. ${ }^{89}$ Under Medicaid rationing they give up potentially life-saving experimental transplants of some kinds, for which there is a very low probability that they will have the relevant need, in exchange for a broad array of health services which they are most likely to need. This is not a perfectly just exchange, and it does not emerge from a democratic conversation characterized by undominated equality. But elsewhere I have

85 See, e.g., Oregon Medicaid Rationing Experiment: Hearing Before the Subcomm. on Health and the Environment of the House Comm. on Energy and Commerce, 102d Cong., 1st Sess. 116, 117 (1991) (statement of Robert J. Castagna, Executive Director, Oregon Catholic Conference; outlining the Oregon Catholic Conference's stance that Oregon's approach threatens the basic rights of the poor).

${ }^{86}$ See Leonard M. Fleck, The Oregon Medicaid Experiment: Is It Just Enough?, 9 BUS.

\& Prof. ETHICS J. 201, 211-14 (1990).

87 See id. at 212.

${ }^{88}$ See id. at 211.

${ }^{89}$ See id. at 211-12. 
made a case for saying that it is "just enough" in a nonideal world in the political circumstances that Oregon itself has no control over. ${ }^{90}$ Along these same lines Eddy offers a useful thought experiment: if the proposed Medicaid rationing program were now in place in Oregon, and if Oregon appealed to Congress for a Medicaid waiver to put in place what they currently have $(400,000$ uninsured; Medicaid for only fifty-eight percent of the poor) would Congress enthusiastically grant that waiver on the grounds that the poor would be better off? ${ }^{91}$

What would be better, and why would it be better? In Michigan the Medical Ethics Resource Network of Michigan and the Center for Ethics and Humanities in the Life Sciences at Michigan State University have launched a statewide democratic consensus-building project: "Just Caring: Conflicting Rights, Uncertain Responsibilities." 92 The project will occur at twenty to twenty-five sites, with fifty project participants at each site-individuals who are in leadership roles and broadly representative of the community at large. Each site will hold twenty-five to thirty public forums over a two-year period in which those fifty individuals will participate. The public is invited to attend those formal conversations. For each session, a reading packet is provided to project participants so that we have an informed public conversation. Each session has a very detailed issue agenda and discussion questions that link the readings to it. For example, the issue for the evening might be justice and resource allocation for severely impaired infants. We would have several very concrete cases, like that of Michael, which would illustrate the range of decisions that need to be made. The objective for the session would be to see whether we could come to a tentative consensus on some considered judgments of health care justice that will assist us in framing morally justifiable social policy in this area. University faculty serve as facilitators of this democratic conversation, but there will be virtually no lecturing in these public forums. Though participants in the conversation bring their social roles with them (e.g., physician, corporate vice-president), they are not there to defend the interests of the group they might represent, and they are urged to speak to one another as free and

90 See id. at 211-14.

91 See Eddy, supra note 80 , at 2445.

92 The interested reader may write to Leonard Fleck for a 15-page project booklet that describes the "Just Caring" project in detail. 
equal citizens (undominated equality) so that the conversation advances by force of reason, not political pressure.

The general idea in these conversations is that over a long enough period of time a large number of these tentative considered judgments of health care justice would emerge from case scenarios across the health care spectrum. Those judgments would have to be brought into balance with one another since they are all part of the sphere of health care justice. The objective would be to achieve a kind of reflective equilibrium that was "just enough" from the point of view of Eddy's Patient, that is, just enough to all the possible future selves that are me and just enough to all those other selves that comprise my society. Again, the consensus that we seek regarding health care justice is as much within ourselves as it is among ourselves.

Bruce Ackerman speaks of "constitutional moments," defining political moments in the life of a society. ${ }^{93}$ That analogy captures well what the "Just Caring" project is about; for, in important respects, we are at a defining moment in the arena of health care politics and policy. We are in need of a "health care constitution," which is what we expect to emerge at the end of this two-year process. ${ }^{94}$ More specifically, the goals of the "Just Caring" project are to: (1) articulate a comprehensive and coherent conception of health care justice that speaks to our problems of health care justice; (2) identify what we judge to be the most serious injustices and inefficiencies in our current health system and health policy; (3) articulate a set of basic social values and considered judgments of justice that just and costworthy health policies in our society must satisfy; (4) articulate a set of principles for priority setting among

${ }^{93}$ See Bruce A. Ackerman, The Storrs Lectures: Discovering the Constitution, 93 YALE L.J. 1013, 1056 (1984).

${ }_{94}$ For Ackerman legislative politics, or politics as usual, would be completely inadequate during constitutional moments. See id. at 1055-56. The argument of this essay is that we are at such a moment, at least within the sphere of health care policy. Citizen/patients must seize the initiative. To leave health care reform to legislators and administrators is to guarantee that we will have a health care system that is neither fair nor efficient. Creating a constitution is a supreme political act of autonomy through which is fashioned solidarity among a people, at least if all have had an opportunity to participate in that act. A constitution is a comprehensive document that brings together and balances numerous political values. A constitution creates the stability needed to sustain an effective sense of justice across generations. Hence, what we need at the basis of health care reform is a constitution that articulates our collective sense of what a just and caring society ought to be when it comes to both providing and limiting access to health care. 
health needs that best capture what a just and caring society (constrained by resource limits) ought to be; and (5) articulate a comprehensive set of policy options for financing health care, expanding access to adequate health care, and containing health costs that are congruent with the priority setting principles and basic social values to which we will have committed ourselves. ${ }^{95}$

What we are engaged in here is not some abstract philosophic conversation. The conversation moves freely back and forth from cases like that of Michael or Helga Wanglie to the level of social policy (what should we do in the way of resource allocation for 6000 infants like Michael or 10,000 patients in a persistent vegetative state?) to the level of the broader social values we want to affirm. Moreover, what is affirmed and repeated and emphasized throughout the conversation is that we are not talking about the fate of strangers or distant others in our society. Rather, we are talking about our future possible selves, who might be afflicted with Alzheimer's, suffer from a form of cancer where a $\$ 150,000$ bone marrow transplant is the only hope for survival, have a grandchild like Michael, get AIDS, or have an unemployed brother without health insurance, and so on.

The philosopher John Rawls is well known for his "veil of ignorance" thought experiment wherein all members of our society have to talk to one another about what basic principles of justice we want operative in our society. ${ }^{96}$ This conversation occurs behind a veil of ignorance where all of us are like disembodied spirits who know nothing at all about ourselves as individuals. The general idea is that this facilitates choosing principles from an impartial point of view. This looks like something philosophically interesting, but having no possibility of real world exemplification. In the matter of health care, however, the vast majority of us are like Rawls's disembodied spirits behind that veil of ignorance. We are capable

${ }^{95}$ Elsewhere in this Issue Professor Leslie Francis speaks to the problem of vague consumer expectations about access to health care, the kind of now very costly expectations that many retirees have with regard to health benefits they have been "promised." See Leslie Pickering Francis, Consumer Expectations and Access to Health Care, 140 U. PA. L. REV. 1881 (1992). The virtue of the "Just Caring" project in particular, and the democratic consensus approach it exemplifies, is that it provides a public mechanism through which we can explicitly and mutually affirm what should count as just and reasonable health care expectations regarding societally provided health care. Moreover, this can be (and must be) a moving reflective equilibrium that is constantly responsive to changes required by emerging medical technologies.

${ }^{96}$ See Rawls, Kantian Constructivism, supra note 3, at 522-23. 
of a rare degree of impartiality because we really do not know enough about our future health needs.

The post-World War II "baby boom" generation is in middle age now. And, as mentioned earlier, the elderly are the largest disproportionate users of health services in our society. There are approximately thirty-one million elderly now, but by the year 2030 there will be sixty-two million, representing a very large percentage of the population. ${ }^{97}$ The thought of age-rationing is seen by many as a morally vile option-and it is, if what we imagine is the healthy young denying the infirm elderly life-sustaining care. The alternative is that we who are now in middle age make rationing decisions about our future elderly selves. There does not appear to be anything intrinsically abhorrent morally about that alternative, and those are precisely the kinds of choices that can be appropriately made through the informed democratic consensus approach embodied in the "Just Caring" project.

In summary, what are the moral and political virtues of the informed democratic consensus model for health care rationing as embodied in "Just Caring"? First, rationing decisions are visible, explicit, and open to critical assessment. Second, rationing decisions are freely self-imposed. No one is coercively imposing these decisions on weak or vulnerable others. What we need to make are hard choices for ourselves and those we care about. Third, what occurs here is a comprehensive and coherent approach to health care rationing. We have no moral footing at all when we are expected to make rationing decisions about Michael or Helga Wanglie as isolated cases. There is ample opportunity in such situations for completely arbitrary decisions. But the point of having a two-year conversation is that we then have a comprehensive moral framework that allows us to make reflective balancing and trade-off decisions. In fact, a fuller description of this model would describe it as "constrained" democratic consensus; for, as the conversation evolves and we deal with a broader range of specific problems of health care rationing, we will find ourselves rationally and morally constrained by the value commitments and considered

${ }^{97}$ See Edward L. Schneider \& Jack M. Guralnik, The Aging of America: Impact on Health Care Costs, 263 JAMA 2335, 2337 (1990). As these authors point out, not all the elderly are equally costly. Older age cohorts among the elderly are generally more costly than younger cohorts. See id. What they find most troubling is that the "oldest old," those over age 85, will grow substantially over the next several decades, see id. at 2335-36, the result being a sixfold increase by the year 2040 in Medicare costs for this group in constant 1987 dollars, see id. at 2335. 
judgments of health care justice made earlier, in much the same way that legal precedent works. This is how we can achieve democratically and liberally a reflective equilibrium regarding health care justice that has rational moral substance (as opposed to being an arbitrary product of public opinion).

\section{CONCLUSION}

In conclusion, I have argued that the problem of health care rationing is fundamentally a moral problem, and that the only way in which decisions can be made fairly is through processes that are visible and public and yield rationing principles and protocols that are self-imposed. The informed democratic consensus model I have sketched is the only approach to health care rationing with which I am familiar that meets all those conditions. That does not mean there is no appropriate role for markets or bureaucratic approaches to health care rationing. It only means that the legitimate use of these other approaches will be morally constrained by what emerges from that informed democratic consensus. For example, the working assumption of this essay has been that non-costworthy health care is beyond justice. That is, a society that chooses to exclude such health services from the package of services guaranteed to all has treated no one unjustly. I realize, of course, that in practice what counts as costworthy health care will be a product of moral, political, economic, and medical judgment. My point is that in the arena of health services beyond justice, which will have been delineated through democratic consensus, market mechanisms may operate freely.

There are individuals who are extremely risk-averse, who may want (and be able to afford) non-costworthy health services that could conceivably be covered by an insurance product of some sort. So long as there is no public subsidy for these insurance products, as there is now through the tax code, and so long as no one else is disadvantaged in terms of access to needed health care by such insurance products, markets for such products will not generate any injustices. Similarly, in the domain of truly experimental medicine considerations of justice articulated through democratic consensus will greatly underdetermine who ought to have access to those experimental therapies. Instead, canons of good clinical research may justifiably exclude individuals who could conceivably benefit from those therapies but whose comorbid conditions will likely confound the scientific reliability of the data. Such individuals will 
not have been treated unjustly because here too we will largely be in a domain beyond justice.

Finally, a theme throughout the essays in this volume is accountability. No other approach to health care rationing fosters accountability as well as does the informed democratic consensus approach. If through broad mechanisms of public deliberation we generate and approve a complex system of rationing protocols aimed at distributing limited health resources as fairly and costeffectively as possible for our future selves, then what we are also saying is that we are responsible for those protocols and their consequences. As things are now, no one is responsible for meeting the health needs of the uninsured and underinsured; no one is responsible for making sure that costworthy, and only costworthy, health care is purchased; no one is responsible for assuring the fairness of various rationing mechanisms. This allows us the psychologically comforting illusion that the excess cancer death rate among the uninsured poor is merely unfortunate rather than clearly unjust. This illusion is sustainable because responsibility for this outcome is so thoroughly diffused among millions of taxpayers (who refuse to pay higher taxes), thousands of physicians (who fail to provide enough charity care), thousands of stingy insurance managers (who are more aggressively resisting cost-shifting efforts for charity care), thousands of state legislators and bureaucrats (who trim Medicaid rolls and benefits and payment levels to balance state budgets), and the uninsured poor themselves (who should have worked harder, saved money for health insurance, and been more attentive to their health in the first place).

There are alternative approaches to assuring accountability for health care rationing: physicians at the bedside can take that responsibility, or else government bureaucrats can fashion very detailed rationing protocols. If physicians at the bedside are given that responsibility, then we would almost certainly compromise trust and integrity in the doctor-patient relationship. On the other hand, if government bureaucrats take on that responsibility, then the perception of citizen-patients denied wanted but non-costworthy health care will be that uncaring, indifferent, ignorant outside parties are unjustly depriving them of life and liberty. That is, these citizen-patients can effectively deny that they themselves have any responsibility for making these rationing decisions.

In the final analysis both bedside physicians and some sort of governmentally legitimated entity (the health congress) will have responsibility for precisely articulating and implementing a set of 
explicit rationing protocols. But the moral and political legitimacy of those protocols will ultimately have to be derived from the informed democratic consensus we described above, which correctly locates responsibility for these decisions in each of us and all of us. If we (democratic citizens) do not want rationing protocols coercively imposed upon us, then we need to make these choices for ourselves. If we want a health care system that is just and caring and costworthy, and that reflects our conception of these basic values, then we (as future patients but present premium payers/ taxpayers) will have to take responsibility for making these choices and trade-offs for ourselves. Contrary to Calabresi and Bobbitt, these are not tragic choices with which we are faced. Rather, the real tragedy would be failing to take this responsibility. The real tragedy would be continued moral indifference to the implicit (and irresponsible) rationing mechanisms (markets, Medicare DRGs) that currently constrain our health costs at the expense of justly needed health care by others. 